\title{
Effect of class II extractions and functional appliance treatment on smile esthetics
}

\section{Wpływ ekstrakcji i leczenia czynnościowego wad zgryzu klasy II na estetykę uśmiechu}

\author{
Umair Shoukat Ali ${ }^{A, B, D}$, Rashna Hoshang Sukhia ${ }^{C, E, F}$, Mubassar Fida ${ }^{A, F}$ \\ Aga Khan University and Hospital, Karachi, Pakistan \\ A - research concept and design; $B$ - collection and/or assembly of data; $C$ - data analysis and interpretation; \\ $D$ - writing the article; $E$ - critical revision of the article; $F$ - final approval of the article
}

\section{Address for correspondence \\ Rashna Hoshang Sukhia \\ E-mail: rashna_aga@yahoo.com}

\section{Funding sources}

None declared

Conflict of interest

None declared

Received on July 12, 2019

Reviewed on November 5, 2019

Accepted on December 9, 2019

Published online on June 30,2020

\section{Cite as}

Ali US, Sukhia RH, Fida M. Effect of class II extractions and functional appliance treatment on smile esthetics. Dent Med Probl. 2020;57(2):157-163. doi:10.17219/dmp/115169

D0I

$10.17219 / \mathrm{dmp} / 115169$

Copyright

๑ 2020 by Wroclaw Medical University

This is an article distributed under the terms of the

Creative Commons Attribution 3.0 Unported License (CC BY 3.0)

(https://creativecommons.org/licenses/by/3.0/).

\begin{abstract}
Background. Class II malocclusion is routinely observed in orthodontics. Its treatment usually revolves around the growth modification or the extractions of the teeth. Identifying treatment that leads to the greatest improvement can aid clinicians in providing the desired smile esthetics.

Objectives. The aim of the study was to compare smile esthetics between treatment groups by measuring various smile variables and the esthetic perceptions of 3 panels of raters.

Material and methods. A cross-sectional study was performed on 66 patients equally divided into the functional appliance (FA) and upper first premolar extraction (UPE) groups. Eight smile variables were measured on post-treatment photographs using the Adobe Photoshop ${ }^{\circledR}$ software. Ten orthodontic residents, general dentists and laypersons performed the subjective evaluations of smiles using the visual analog scale (VAS). The Mann-Whitney U-test was applied to compare smile variables between the groups. The Kruskal-Wallis test was used to compare esthetic scores (ES) among the raters. The simple linear regression analysis, followed by the multiple linear regression analysis was applied to determine the smile variables associated with the ES values.
\end{abstract}

Results. Statistically significant differences were found between the FA and UPE groups for the buccal corridor ratio (BCR) $(p=0.046)$, the visible dentition width ratio (VDWR) $(p=0.019)$ and the arch form index (AFI) ( $p<0.001)$. The Kruskal-Wallis test showed significant differences in ES among the raters for the FA $(p<0.001)$ and UPE $(p=0.004)$ groups. The simple linear regression analysis showed significant associations between $E S$ and the patient's age $(p=0.002), \operatorname{BCR}(p=0.020)$ and VDWR $(p=0.006)$. The multiple linear regression analysis showed that age $(p=0.008)$ and VDWR $(p=0.021)$ were significantly associated with the ES values.

Conclusions. The FA group had narrower buccal corridor spaces, a greater visible dentition width and a wider arch form in their smiles. The UPE group showed an increase in the buccal corridor width. Each panel rated the FA appliance group as superior.

Key words: orthodontic appliances, malocclusion, Angle class II, smile

Słowa kluczowe: aparaty ortodontyczne, nieprawidłowy zgryz, wada zgryzu klasy II Angle'a, uśmiech 


\section{Introduction}

Smile esthetics is the primary focus of orthodontic treatment in the contemporary age. An esthetic smile can boost a person's confidence, and improve social interaction and quality of life. ${ }^{1,2}$ It is crucial for an orthodontist to be able to assess smile esthetics and meet the patient's expectations. ${ }^{3}$ According to Goldstein, the smile is one of the most fundamental features of facial attractiveness. ${ }^{4}$ Ackerman and Ackerman suggested that even with successfully treated orthodontic patients, obtaining ideal smile esthetics is challenging for experienced practitioners. ${ }^{5}$

Class II malocclusion occurs at rates of approx. $24.5 \%$ in Asians, 33\% in Caucasians and $15 \%$ in the US population. ${ }^{6-8}$ In most cases, mandibular retrognathism is the culprit of skeletal class II malocclusion, giving patients a characteristic convex profile. ${ }^{8,9}$ Hence, enhancing the mandibular growth in pre-adolescent patients is indicated to improve mandibular deficiency. ${ }^{10}$ The growth modification of the mandible depends on the skeletal maturational age of the patient as assessed by the cervical maturation index proposed by Baccetti et al. ${ }^{11}$ Functional appliances improve skeletal disharmony during the growth period (CS (cervical stage)-3) by posturing the mandible forward and stimulating the mandibular growth. ${ }^{12}$ An example of a commonly used functional appliance is Clark's twin block (CTB). ${ }^{13}$ However, once the desired results of functional appliance treatment are achieved, a brief course of fixed mechanotherapy is required to finish the process.

If, on the other hand, the patient has surpassed their growth potential (CS-5-CS-6), class II correction is confined to either orthodontic camouflage or orthognathic surgery. ${ }^{14}$ Orthodontic camouflage is defined as masking the skeletal discrepancies of the face without correcting the underlying jaw disharmony. ${ }^{14,15}$ A majority of orthodontic patients prefer to avoid orthognathic surgery, as it is invasive, and instead opt for camouflage. ${ }^{16}$ Orthodontic camouflage is suitable for patients with average or short facial patterns, mild anteroposterior jaw discrepancies, crowding <4-6 mm, and normal soft tissues. ${ }^{17}$ Class II camouflage is most commonly achieved with the extraction of the upper first premolars. ${ }^{18}$

The evaluation of smile esthetics at the end of orthodontic treatment can provide useful information on how different modalities affect the perception of smile esthetics. Therefore, the identification of treatment that leads to the greatest improvement of facial esthetics can aid clinicians in selecting appropriate treatment modalities. The objectives of this study were to compare smile esthetics in patients who underwent functional appliance therapy followed by fixed mechanotherapy and those who underwent fixed appliance therapy with upper first premolar extraction, and to evaluate the esthetic perceptions of 3 panels of raters, including orthodontic residents, general dentists and laypersons. The null hypothesis was that there would be no difference between the 2 treatment groups in terms of smile esthetics as perceived by the raters.

\section{Material and methods}

A cross-sectional study that included 66 participants was performed after obtaining approval from the Aga Khan University ethics review board (2018-0295-161), Karachi, Pakistan. Data was obtained from the post-treatment follow-up frontal smiling photographs of subjects treated for skeletal class II malocclusion. These patients had been treated consecutively over a period of 4 years (2013-2017) at the Orthodontic Clinic, with post-treatment followups advised every 6 months.

The sample size was calculated using the OpenEpi ${ }^{\circledR}$ software v. 3.01 (www.openepi.com), taking into account the findings of Johnson and Smith, who reported a mean inter-canine-visible dentition width of $0.77 \pm 0.032 \mathrm{~mm}$ for non-extraction treatment and $0.80 \pm 0.050 \mathrm{~mm}$ for extraction treatment. ${ }^{19}$ Keeping $\alpha=0.05$ and a power of $80 \%$, a total of 31 subjects were required in each group. Since we had 2 groups, a total sample of 62 was required. This value was inflated to include 33 subjects per group. The samples were divided into the functional appliance (FA) group (CTB) and the upper first premolar extraction (UPE) group. The mean age of our sample groups at the post-treatment follow-up was $20.3 \pm 1.2$ years for the FA group and $23.3 \pm 2.8$ years for the UPE group. The gender distribution for the FA group was 15 males and $18 \mathrm{fe}$ males; for the UPE group, it was 14 males and 19 females.

\section{Inclusion criteria}

\section{Functional appliance group}

The inclusion criteria for the FA group were as follows: skeletal class II patients with $\mathrm{ANB}>6^{\circ}$, a normal or low vertical facial growth pattern, proclined upper incisors (UI-SN $>107^{\circ}$ ), and normal or retro-lined lower incisors $\left(\mathrm{IMPA}<90^{\circ}\right)$ with a procumbent lower lip due to mandibular deficiency. The patients in this group had existent growth potential (CS-3) on lateral cephalograms according to the classification by Baccetti et al. ${ }^{11}$ The CTB bite registration for advancing the mandible was obtained as recommended by Profitt et al. (4-6 mm of sagittal advancement and $3-4 \mathrm{~mm}$ of vertical opening). ${ }^{8}$ Two-phase therapy was performed, starting with phase I - the growth modification with a removable CTB for a mean duration of $11.0 \pm 1.3$ months; phase II - the final finishing and detailing - was performed in this group with fixed appliances (Roth prescription 0.022 -inch slots) for a mean duration of $12.2 \pm 2.1$ months.

\section{Upper first premolar extraction group}

The patients in the UPE group had comparable cephalometric characteristics to the FA group, except that they had mild mandibular deficiency $\left(4^{\circ}<\mathrm{ANB}<6^{\circ}\right)$ with minimal or no growth potential left (CS-5 or CS-6) to plan for the growth modification. The selected patients had dental 
class II molar relationships (end-on, 3/4 or full cusp). No extractions were done in the lower arch, since no discrepancies or crowding were present. ${ }^{20}$ Single-phase treatment with comprehensive fixed appliance therapy was performed (Roth prescription 0.022-inch slots) for a mean duration of $27.4 \pm 1.1$ months. After upper first premolar extraction, the patients underwent the retraction of the canines on 0.018-inch stainless steel (SS) wires followed by the retraction of the incisor segments via looped mechanics on 0.017-inch $\times$ 0.025-inch SS wires.

\section{Exclusion criteria}

The exclusion criteria were any previous history of orthodontic or orthopedic treatment, any craniofacial/dental anomaly or syndrome, a history of trauma or surgery involving facial structures, or any skeletal discrepancy in which camouflage was not indicated.

\section{Procedures}

Post-treatment follow-up frontal smiling photographs were taken for each participant using a Sony ${ }^{\circledR}$ DSC-WX200 digital camera (maximum resolution
$4896 \times 3672$, approx. 18.2 megapixels) (Sony Corp., Tokyo, Japan); the pictures were stored in the JPEG format. To standardize the images, we followed the guidelines published by Desai et al. ${ }^{21}$ and Chetan et al. ${ }^{22}$ The camera was affixed to a tripod approx. $4 \mathrm{ft}$ from the standing subject. While taking the photographs, the patients were asked to look straight into an imaginary mirror, holding their head in a natural position. The camera was adjusted to the position parallel to the apparent occlusal plane. The grid ruler option was used in the camera, so that the capture area was situated in the center of the frame. Both ears of the patient were equally visible to ensure there was no error of orientation in the transverse plane. While the frontal smiling photographs were being taken, the patients were asked to say 'seven' or 'cheese'. The continuous shooting mode (burst mode) was used to take multiple images and the best picture, in which all the necessary anatomical landmarks were captured, was selected for each patient. Evaluations were made using the Adobe Photoshop ${ }^{\circledR}$ software (Adobe, San Jose, USA).

The perioral area was cropped and 8 smile variables were measured as ratios to limit the bias and compensate for the magnification differences among the pictures (Fig. 1). ${ }^{23}$

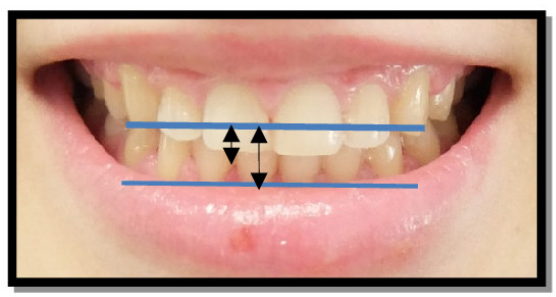

smile arc ratio (SAR) - distance from the maxillary incisal edge to the inter-canine connecting line divided by the distance from the lower lip to the inter-canine connecting line

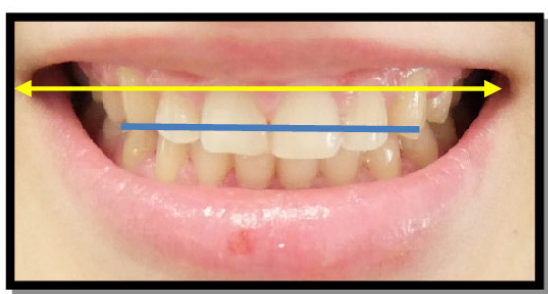

buccal corridor ratio (BCR) - inter-commissure width divided by the inter-canine width

Fig. 1. Smile variables

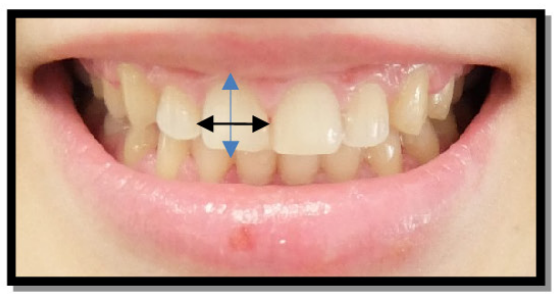

maxillary incisor display (MID) - distance from the maxillary incisal edge to the upper lip divided by the maxillary incisor width

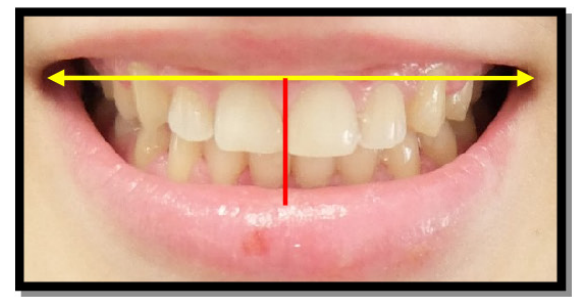

smile index (SI) - inter-commissure width divided by the interlabial gap

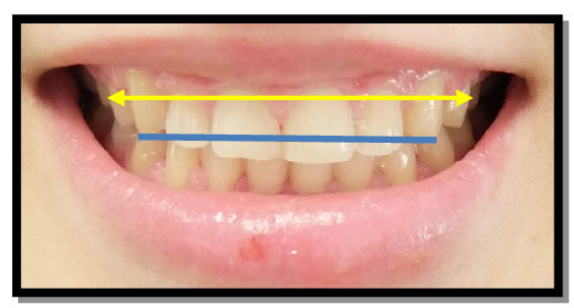

visible dentition width ratio (VDWR) - maxillary inter-canine width divided by the visible dentition width

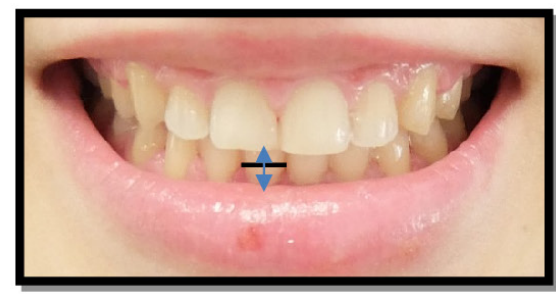

mandibular teeth exposure (MTE) - visible mandibular incisor length

divided by the mandibular incisor width

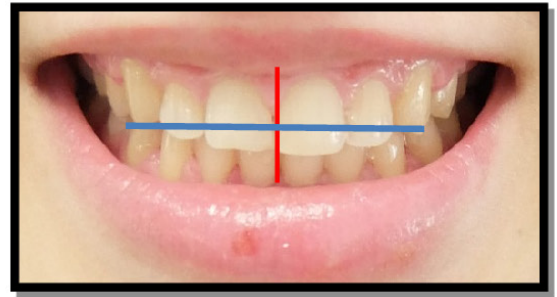

interlabial gap ratio (ILGR) - lip separation during a smile divided by the inter-canine width

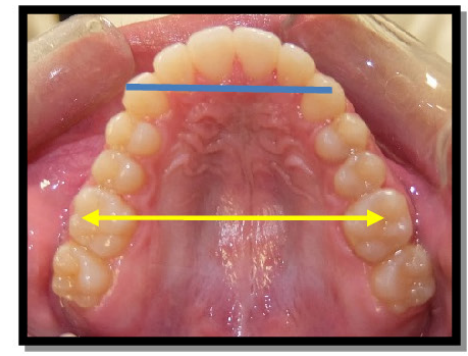

arch form index (AFI) - inter-canine width divided by the inter-molar width 
The measured smile variables were as follows: the smile arc ratio (SAR) - the distance from the maxillary incisal edge to the inter-canine connecting line divided by the distance from the lower lip to the inter-canine connecting line; maxillary incisor display (MID) - the distance from the maxillary incisal edge to the upper lip divided by the maxillary incisor width; mandibular teeth exposure (MTE) - the visible mandibular incisor length divided by the mandibular incisor width; the buccal corridor ratio (BCR) - the inter-commissure width divided by the intercanine width; the smile index (SI) - the inter-commissure width divided by the interlabial gap; the interlabial gap ratio (ILGR) - lip separation during a smile divided by the inter-canine width; the visible dentition width ratio (VDWR) - the maxillary inter-canine width divided by the visible dentition width; and the arch form index (AFI) - the inter-canine width divided by the inter-molar width.

Subjective assessments were made by different panels of raters, which included 10 orthodontic residents, 10 general dentists and 10 laypersons. Each participant's frontal smiling photograph was analyzed and scored on a visual analog scale (VAS). It was created on a 100-millimeter uninterrupted line, anchored at 0 on the left (very unattractive) and at 10 on the right (very attractive). ${ }^{23}$

The panel of orthodontic residents consisted of $6 \mathrm{fe}$ males and 4 males of a mean age of $28.6 \pm 2.1$ years. In the general dentist panel, there were 6 females and 4 males of a mean age of $27.5 \pm 2.3$ years. In the layperson panel, we had 4 females and 6 males of a mean age of $22.8 \pm 1.4$ years.

To test the intra-examiner reliability, 10 frontal smiles were randomly selected and re-measured by the principal investigator. The intra-class correlation coefficient (ICC) showed values ranging from 0.85 to 1.0 between the 2 sets of measurements, indicating excellent agreement.

The data was analyzed by means of the IBM SPSS Statistics for Windows software, v. 20.0 (IBM Corp., Armonk, USA). Descriptive statistics were applied to calculate the mean age and distribution by gender. The Shapiro-Wilk test yielded a non-normal distribution of the sample. The Mann-Whitney $U$-test was used for the comparison of smile variables in the FA and UPE treatment groups. The one-way analysis of variance (ANOVA) was used to compare smile esthetic scores (ES) among the 3 panels of raters. The simple and multiple linear regression analyses were used to evaluate the variables which affected the subjective smile ES for both treatment groups. A $p$-value $\leq 0.05$ was considered statistically significant.

\section{Results}

The comparisons of smile variables between the 2 treatment groups showed BCR $(p=0.046)$, VDWR $(p=0.019)$ and AFI $(p<0.001)$ to be significantly higher in the UPE group (Table 1).
Table 1. Comparison of smile variables between the functional appliance (FA) and upper first premolar extraction (UPE) treatment groups

\begin{tabular}{|l|c|c|c|}
\multirow{2}{*}{$\begin{array}{l}\text { Variable } \\
\text { (ratio })\end{array}$} & \multicolumn{2}{|c|}{ Treatment group } & \\
\cline { 2 - 3 } & $\begin{array}{c}\text { FA } \\
(n=33)\end{array}$ & $\begin{array}{c}\text { UPE } \\
(n=33)\end{array}$ & \\
\hline SAR & $0.50(0.40,0.65)$ & $0.50(0.40,0.64)$ & 0.831 \\
MID & $0.95(0.80,0.95)$ & $0.97(0.77,1.14)$ & 0.681 \\
MTE & $0.66(0.56,0.78)$ & $0.60(0.00,0.85)$ & 0.535 \\
BCR & $1.52(1.40,1.60)$ & $1.62(1.50,1.70)$ & $0.046^{*}$ \\
SI & $4.80(4.40,4.80)$ & $5.10(4.50,6.00)$ & 0.534 \\
ILGR & $0.31(0.25,0.36)$ & $0.31(0.26,0.36)$ & 0.724 \\
VDWR & $1.29(1.21,1.34)$ & $1.39(1.26,1.43)$ & $0.019^{*}$ \\
AFI & $0.78(0.74,0.79)$ & $0.84(0.81,0.87)$ & $<0.001^{* *}$ \\
\hline
\end{tabular}

Data presented as median (interquartile range) (Me (IQR)).

SAR - smile arc ratio; MID - maxillary incisor display; MTE - mandibular teeth exposure; BCR - buccal corridor ratio; SI - smile index; ILGR - interlabial gap ratio; VDWR - visible dentition width ratio; AFI - arch form index; ${ }^{*} p \leq 0.05$; ${ }^{* *} p<0.001$; Mann-Whitney U-test.

The comparisons of the ES provided by the different panels of raters showed statistically significant differences among the raters for the the FA group $(p<0.001)$ and the UPE group $(p=0.004)$. Among the raters, orthodontic residents and laypersons gave higher scores to both the treatment groups than general dentists did. However, while comparing the treatment groups, all 3 panels of raters preferred the FA group over the UPE group (Table 2 ).

Table 2. Comparison of smile perceptions using the esthetic scores (ES) of 3 groups of raters

\begin{tabular}{|l|c|c|c|c|}
\hline $\begin{array}{c}\text { Treatment } \\
\text { group }\end{array}$ & $\begin{array}{c}\text { Orthodontic } \\
\text { residents } \\
(n=10)\end{array}$ & $\begin{array}{c}\text { General } \\
\text { dentists } \\
(n=10)\end{array}$ & $\begin{array}{c}\text { Laypersons } \\
(n=10)\end{array}$ & $p$-value \\
\hline FA & $56(47,65)$ & $43(35,46)$ & $58(50,63.5)$ & $<0.001^{* *}$ \\
UPE & $51(41,60)$ & $41(36,52)$ & $48(38,61)$ & $0.004^{*}$ \\
\hline
\end{tabular}

Data presented as Me $(I Q R)$.

${ }^{*} p \leq 0.05$; ${ }^{* *} p<0.001 ;$ Kruskal-Wallis test.

The simple linear regression analysis showed that age $(p=0.002), \operatorname{BCR}(p=0.020)$ and VDWR $(p=0.006)$ were negatively correlated with the mean ES of the raters (Table 3 ); the correlations were statistically significant. Age $\left(R^{2}=0.13\right)$ explained $13 \%$ of the variability in the mean ES values, whereas BCR $\left(R^{2}=0.07\right)$ and VDWR $\left(R^{2}=0.11\right)$ accounted for $7 \%$ and $11 \%$ of the variability, respectively.

The multiple linear regression was applied to the variables which were found to be significant in the simple linear regression analysis. Age $(p=0.008)$ and VDRW ( $p=0.021)$ were again found to be statistically significant. Age and VDWR $\left(R^{2}=0.181\right)$ each explained $18 \%$ of the variability in the mean ES values (Table 4 ). 
Table 3. Effect of smile variables on ES

\begin{tabular}{|l|c|c|c|c|}
\hline Variable & $\begin{array}{c}\text { Crude beta } \\
\text { coefficient } \\
(M \pm S D)\end{array}$ & $95 \%$ Cl & $R^{2}$ & $p$-value \\
\hline $\begin{array}{l}\text { Treatment } \\
\text { modality }\end{array}$ & $2.49 \pm 2.70$ & $(-2.90,7.88)$ & 0.013 & 0.350 \\
Gender & $-0.35 \pm 2.80$ & $(-6.00,5.28)$ & $<0.001$ & 0.900 \\
Age & $-0.63 \pm 0.20$ & $(-1.03,-0.23)$ & 0.130 & $0.002^{*}$ \\
[years] & $0.29 \pm 1.40$ & $(-2.60,3.20)$ & $<0.001$ & 0.840 \\
SAR & $-3.80 \pm 4.80$ & $(-13.40,5.86)$ & 0.009 & 0.430 \\
MID & $-0.24 \pm 1.99$ & $(-4.23,3.70)$ & $<0.001$ & 0.900 \\
MTE & $-19.40 \pm 8.33$ & $(-36.12,2.81)$ & 0.070 & $0.020^{*}$ \\
BCR & $1.16 \pm 1.07$ & $(-0.97,3.30)$ & 0.018 & 0.280 \\
SI & $-9.60 \pm 7.79$ & $(-25.18,5.97)$ & 0.020 & 0.220 \\
ILGR & $-31.60 \pm 11.11$ & $(-53.80,-9.42)$ & 0.110 & $0.006^{*}$ \\
VDWR & $1.70 \pm 7.80$ & $(-13.91,17.43)$ & $<0.001$ & 0.820 \\
\hline AFI & 0 & & \\
\hline
\end{tabular}

$N=66 ; M$ - mean; SD - standard deviation; Cl - confidence interval;

* $p \leq 0.05$; simple linear regression analysis.

Table 4. Multiple regression analysis of the smile variables affecting ES

\begin{tabular}{|l|c|c|c|c|}
\hline $\begin{array}{c}\text { Treatment } \\
\text { group }\end{array}$ & $\begin{array}{c}\text { Crude beta } \\
\text { coefficient } \\
(M \pm S D)\end{array}$ & $95 \% \mathrm{Cl}$ & $p$-value & $\begin{array}{c}R^{2} \\
\text { adjusted }\end{array}$ \\
\hline Age [years] & $-0.53 \pm 0.19$ & $(-0.93,-0.14)$ & $0.008^{*}$ & 0.181 \\
VDWR & $-25.66 \pm 10.82$ & $(-47.28,-4.03)$ & $0.021^{*}$ & \\
\hline
\end{tabular}

$N=66 ;{ }^{*} p \leq 0.05$; multiple linear regression analysis.

\section{Discussion}

This study was conducted to evaluate the effects of functional appliances and upper first premolar extraction therapy on smile esthetics. Various studies have been conducted to evaluate and compare the smile esthetics achieved with different treatment modalities. ${ }^{20,21-25}$ In this study, we calculated the ratios to minimize the magnification errors and the measurement bias. However, since a ratio is affected by both its numerator and its denominator, it would be interesting to shed light on the factors that lead to changes in those ratios, and ultimately in smile esthetics. To our knowledge, this is the first study to evaluate the effects of removable functional appliances (CTB) and upper first premolar extraction on smile esthetics. According to our results, we rejected the null hypothesis in favor of the FA group, as the ES values given by the different panels of raters were higher for the FA group.

A review of the literature shows that numerous studies have found no differences between extraction and nonextraction treatment in terms of the eventual esthetic outcome. ${ }^{20,24}$ In our study, we found statistically significant differences in BCR, VDWR and AFI between patients who underwent FA and UPE treatment. The extractions of teeth cause a reduction in the inter-molar width, leading to the constriction of the dental arches at the posterior dental segments. This reflects the mesial movement of the posterior teeth into narrower parts of the arch. ${ }^{25}$ Similarly, we found that the extraction of the upper first premolars produced the constriction of the upper arch. A reduction in the inter-molar width in the UPE group resulted in a greater AFI value, implying that UPE resulted in a narrower upper arch. This is in concordance with the findings of Cheng and Wang. ${ }^{23}$ However, Johnson and Smith argued against the constriction of the dental arch after premolar extractions and pointed out deficiencies in the interpretation of these measurements. ${ }^{19}$ We routinely perform maxillary expansion in conjunction with functional appliance treatment to facilitate class II correction, and this had an impact on the inter-molar width in this treatment group, leading to better and wider smiles.

Maxillary incisor display and the smile arc are among the most crucial aspects of smile esthetics. Improving MID and the smile arc either by increasing or decreasing incisal display can enhance smile esthetics. The MID value highlights the amount of incisal and gingival display while smiling. A higher MID ratio would suggest an increased incisal and gingival display during a smile. We found the UPE group to have a greater MID ratio owing to the retraction of the upper teeth, which is in agreement with a recent study by Cheng and Wang. ${ }^{23}$ Similarly, Cheng and Wang also reported that their FA (non-extraction) group relied upon the expansion of the upper arch to gain space. This in turn resulted in a reduced incisal display and flattened smile arcs. ${ }^{23}$ We also measured SAR, which is the depth of the arcs of curvature for the lower lip and the upper incisor teeth; a ratio of 1.0 would suggest a consonant and esthetic smile. ${ }^{26}$ However, in both our treatment groups, SAR was below 1.0, which concurs with a study conducted by Prasad et al. ${ }^{27}$ Despite all these differences between the 2 treatment groups, both MID and SAR were found to be statistically insignificant in our study. This can be attributed to the precise finishing and detailing received by both treatment groups via fixed labial brackets.

In contrast to MID, MTE during a smile is considered to be a sign of aging. ${ }^{28}$ We found increased MTE and lower lip exposure in the FA group, but this difference was statistically insignificant. Functional appliance treatment might have improved the elasticity of the lower lip musculature, leading to a greater exposure of the lower incisors during a smile, hence the greater ratio. However, MTE had a negative association with ES, which concurs with a study conducted by Cheng and Wang. ${ }^{23}$ Conversely, a study conducted by Prasad et al. found no association between MTE and ES. ${ }^{27}$

To visualize and quantify the frontal smile, Ackerman and Ackerman developed a ratio called the smile index: the inter-commissure width / the interlabial gap. ${ }^{5} \mathrm{~A}$ high SI value indicates a large outer commissural width and/or a small interlabial gap; in other words, a limited smile area. ${ }^{29}$ Since the interlabial gap is the denominator in the equation, a reduction of this denominator increases the ratio. 
We found a reduction in the interlabial gap in the UPE group due to the retraction of the upper and lower lips. The smile index showed a positive association with ES, but it was statistically insignificant, implying that a limited smile area can also be considered acceptable. Our result is in agreement with Ahrari et al., who found that SI had no significant impact on ES. ${ }^{30}$

For a normal vertical growth pattern, Bhavsar et al. reported a mean ILGR of $0.46+0.09$ in a pre-treatment group. ${ }^{31}$ We found considerably reduced ILGRs in both our post-treatment groups as compared to their pretreatment status, but no statistically significant differences were found between the 2 treatment modalities in terms of ILGR. A rationale for this could be that reduced interlabial gap, due to the retraction of the lips, and inter-canine width in the UPE group might have balanced ILGR, leading to similar median scores as in the FA group.

In both genders, minimal buccal corridors are considered attractive. ${ }^{24}$ Narrower dental arches can cause wider buccal corridor spaces, which can be unesthetic. In our sample, we found that the UPE patients had wider buccal corridor spaces due to a reduced maxillary inter-canine width. A reduced maxillary inter-canine width led to an increased BCR in the UPE group. Gianelly found a slightly increased inter-canine width in non-extraction treatment as compared to the extraction of all premolars, which is in agreement with our results. ${ }^{32}$ On the other hand, Yang et al. reported that neither extraction nor non-extraction treatment had any effect on the buccal corridor width. ${ }^{33}$ It has been observed that after the $2^{\text {nd }}$ decade of life, a reduction in the facial muscular tonicity and functionality can decrease the inter-commissure width of the lips during a smile; therefore, the corners of the lips are not stretched apart to the same extent as in the younger age group during a social smile. ${ }^{21}$ Considering these age-related changes, wider buccal corridor spaces apparent in the UPE group at an early age might not be unesthetic in later years. Due to the constriction of the arch, the UPE group also suffered from less visible dentition during a smile, leading to a higher VDWR, implying fewer teeth visible during a smile. Contrary to our findings, Ghaffar and Fida found no significant difference in the visible dentition width while evaluating the impact of the extraction of all first premolars on smile esthetics. ${ }^{34}$ In our study, variables such as SAR, MID, MTE, SI, and ILGR were not significantly different between the treatment groups; this is compatible with the results of other studies. ${ }^{23,33}$

The subjective assessments of smile esthetics made by 3 different panels of raters revealed that orthodontic residents, general dentists and laypersons all preferred the esthetic outcome of the FA group over the UPE group. However, a study conducted by Peck et al. reported that dental professionals' opinions might differ from laypersons' while evaluating the esthetics of frontal close-up smiles. ${ }^{35}$ In contrast, we found no significant differences between the ES values given by laypersons and dental professionals, and our results are in concordance with a study conducted by Ghaffar and Fida. ${ }^{34}$ Although the general dentist group perceived the best esthetic outcomes with FA treatment, their overall ES values were much lower than those of the other raters. This could be due to the presence of white spot lesions or gingival inflammation induced by orthodontic treatment. In comparison, we believe that orthodontic residents scored the finished smile esthetics on the basis of alignment, the inclination of the teeth, coincident dental midlines, and the overall symmetry of the smile. White spot lesions and gingival conditions seemed to have little effect on their ES.

Among the variables we measured, age, BCR and VDWR were found to be statistically significant when compared to the mean ES values using simple linear regression. Age was negatively correlated with the mean ES values; this shows a strong association with better esthetic outcomes of the FA group, in which the patients started treatment at an earlier age. We found that BCR and VDWR were negatively associated with the mean ES values as well. In a computer-based survey, Roden-Johnson et al. reported that the buccal corridors had no influence on the ES values given by orthodontists, dentists and laypersons. ${ }^{36}$ The multiple regression analysis revealed that both age and VDWR were significant factors affecting the ES values given by the raters. However, our multiple regression model can only explain $18 \%$ of the variability in the ES values. We recommend the evaluation of other factors of mini-esthetics and micro-esthetics to better explain the rest of the variability in the ES values.

\section{Conclusions}

Our study compared the esthetic outcomes between functional appliance treatment and premolar extractions in skeletal class II malocclusion. The FA group had narrower buccal corridor spaces, a greater visible dentition width and a wider arch form while smiling. These variables are considered imperative in finishing orthodontic treatment, and providing patients with an attractive and youthful smile. The UPE group showed an increase in the buccal corridor width, a decreased visible dentition width and a narrower arch form during a smile. In the subjective assessments of smile esthetics, each panel preferred the FA group.

\section{Limitations}

A smile is best judged in relation to the whole face, as perceived in the natural world. Moreover, a smile is a dynamic process, which means that capturing the ideal smile in each patient is difficult. While making measurements on the photographs, the lip thickness had some influence on a smile - younger participants had fuller and thicker lips on average, and that had an impact on the measurement of such variables as the inter-commisure width and the interlabial gap. 


\section{ORCID iDs}

Umair Shoukat Ali (D) https://orcid.org/0000-0001-9252-8934

Rashna Hoshang Sukhia (D) https://orcid.org/0000-0001-9210-6432

Mubassar Fida (iD https://orcid.org/0000-0003-4842-9896

\section{References}

1. Davis LG, Ashworth PD, Spriggs LS. Psychological effects of aes thetic dental treatment. J Dent. 1998;26(7):547-554.

2. Işiksal E, Hazar S, Akyalçın S. Smile esthetics: Perception and comparison of treated and untreated smiles. Am J Orthod Dentofacial Orthop. 2006;129(1):8-16.

3. Kiyak HA. Does orthodontic treatment affect patients' quality of life? J Dent Educ. 2008;72(8):886-894.

4. Goldstein RE. Study of need for esthetics in dentistry. $J$ Prosthet Dent. 1969;21(6):589-598.

5. Ackerman MB, Ackerman JL. Smile analysis and design in the digital era. J Clin Orthod. 2002;36(4):221-236.

6. Chew MT. Spectrum and management of dentofacial deformities in a multiethnic Asian population. Angle Orthod. 2006;76(5):806-809.

7. Helm S. Malocclusion in Danish children with adolescent dentition: An epidemiologic study. Am J Orthod. 1968;54(5):352-366.

8. Proffit WR, Fields HW Jr, Moray LJ. Prevalence of malocclusion and orthodontic treatment need in the United States: Estimates from the NHANES III survey. Int J Adult Orthodon Orthognath Surg. 1998;13(2):97-106.

9. Rothstein T, Yoon-Tarlie C. Dental and facial skeletal characteristics and growth of males and females with class II, division 1 malocclusion between the ages of 10 and 14 (revisited) - part I: Characteristics of size, form, and position. Am J Orthod Dentofacial Orthop. 2000;117(3):320-332.

10. Baccetti T, Franchi L, McNamara JA Jr, Tollaro I. Early dentofacial features of Class II malocclusion: A longitudinal study from the deciduous through the mixed dentition. Am J Orthod Dentofacial Orthop. 1997;111(5):502-509.

11. Baccetti T, Franchi L, McNamara JA Jr. An improved version of the cervical vertebral maturation (CVM) method for the assessment of mandibular growth. Angle Orthod. 2002;72(4):316-323.

12. Cozza P, Baccetti T, Franchi L, De Toffol L, McNamara JA Jr. Mandibular changes produced by functional appliances in Class II malocclusion: A systematic review. Am J Orthod Dentofacial Orthop. 2006;129(5):599.e1-e12; discussion e1-e6.

13. Clark WJ. The twin block technique: A functional orthopedic appliance system. Am J Orthod Dentofacial Orthop. 1988;93(1):1-18.

14. Tucker MR. Orthognathic surgery versus orthodontic camouflage in the treatment of mandibular deficiency. J Oral Maxillofac Surg. 1995;53(5):572-578.

15. Proffit WR, Phillips C, Douvartzidis N. A comparison of outcomes of orthodontic and surgical-orthodontic treatment of Class II malocclusion in adults. Am J Orthod Dentofacial Orthop. 1992;101(6):556-565.

16. Stirling J, Latchford G, Morris DO, Kindelan J, Spencer RJ, Bekker HL. Elective orthognathic treatment decision making: A survey of patient reasons and experiences. J Orthod. 2007;34(2):113-127; discussion 111.

17. Guo $Y$, Han X, Xu H, Ai D, Zeng H, Bai D. Morphological characteristics influencing the orthodontic extraction strategies for Angle's class II division 1 malocclusions. Prog Orthod. 2014;15(1):44.

18. Nangia A, Darendeliler M. Finishing occlusion in Class II or Class III molar relation: Therapeutic Class II and III. Aust Orthod J. 2001;17(2):89-94.

19. Johnson DK, Smith RJ. Smile esthetics after orthodontic treatment with and without extraction of four first premolars. Am J Orthod Dentofacial Orthop. 1995;108(2):162-167.

20. Bishara SE, Cummins DM, Jakobsen JR, Zaher AR. Dentofacial and soft tissue changes in Class II, division 1 cases treated with and without extractions. Am J Orthod Dentofacial Orthop. 1995;107(1):28-37

21. Desai S, Upadhyay M, Nanda R. Dynamic smile analysis: Changes with age. Am J Orthod Dentofacial Orthop. 2009;136(3):310.e1-e10; discussion 310-311.

22. Chetan P, Tandon P, Singh GK, Nagar A, Prasad V, Chugh VK. Dynamics of a smile in different age groups. Angle Orthod. 2012;83(1):90-96.
23. Cheng HC, Wang YC. Effect of nonextraction and extraction orthodontic treatments on smile esthetics for different malocclusions. Am J Orthod Dentofacial Orthop. 2018;153(1):81-86.

24. Moore T, Southard KA, Casko JS, Qian F, Southard TE. Buccal corridors and smile esthetics. Am J Orthod Dentofacial Orthop. 2005;127(2):208-213.

25. Kim E, Gianelly AA. Extraction vs nonextraction: Arch widths and smile esthetics. Angle Orthod. 2003;73(4):354-358.

26. Hulsey CM. An esthetic evaluation of lip-teeth relationships present in the smile. Am J Orthod. 1970;57(2):132-144.

27. Prasad V, Tandon P, Singh GK, Nagar A, Maurya RP. Comparison of smile esthetics after extraction and non-extraction orthodontic treatment. IJODR. 2018;4(4):182-189.

28. Van Der Geld P, Oosterveld P, Kuijpers-Jagtman AM. Age-related changes of the dental aesthetic zone at rest and during spontaneous smiling and speech. Eur J Orthod. 2008;30(4):366-373.

29. Sarver DM, Ackerman MB. Dynamic smile visualization and quantification: Part 2. Smile analysis and treatment strategies. Am J Orthod Dentofacial Orthop. 2003;124(2):116-127.

30. Ahrari F, Heravi F, Rashed R, Zarrabi MJ, Setayesh Y. Which factors affect dental esthetics and smile attractiveness in orthodontically treated patients? J Dent (Tehran). 2015;12(7):491-503.

31. Bhavsar A, Nehete AL, Gulve ND, Shah KA, Aher S. Factors affecting smile esthetics in adults with different types of growth patterns. IOSR-JDMS. 2018;17(8):44-50.

32. Gianelly AA. Arch width after extraction and nonextraction treatment. Am J Orthod Dentofacial Orthop. 2003;123(1):25-28.

33. Yang IH, Nahm DS, Baek SH. Which hard and soft tissue factors relate with the amount of buccal corridor space during smiling? Angle Orthod. 2008;78(1):5-11.

34. Ghaffar F, Fida M. Effect of extraction of first four premolars on smile aesthetics. Eur J Orthod. 2011;33(6):679-683.

35. Peck S, Peck L, Kataja M. The gingival smile line. Angle Orthod. 1992;62(2):91-100;discussion 101-102.

36. Roden-Johnson D, Gallerano R, English J. The effects of buccal corridor spaces and arch form on smile esthetics. Am J Orthod Dentofacial Orthop. 2005;127(3):343-350. 